\title{
Effect of High Fidelity Simulation on Nursing Students' Knowledge in Palestine
}

\author{
Nida Jawabreh, Ahmad Ayed, Ahmad Batran \\ School of Nursing, Arab American University, Jenin, Palestine \\ Email: ahmad.juma@aaup.edu
}

How to cite this paper: Jawabreh, N., Ayed, A. and Batran, A. (2019) Effect of High Fidelity Simulation on Nursing Students' Knowledge in Palestine. Open Journal of Nursing, 9, 364-369. https://doi.org/10.4236/ojn.2019.94033

Received: February 26, 2019

Accepted: April 9, 2019

Published: April 12, 2019

Copyright $\odot 2019$ by author(s) and Scientific Research Publishing Inc. This work is licensed under the Creative Commons Attribution International License (CC BY 4.0).

http://creativecommons.org/licenses/by/4.0/

(c) (i) Open Access

\begin{abstract}
Simulation-based teaching ingredients actual patient encounters with high fidelity simulators, mimicking real-time patient scenarios in a realistic, controlled environment. This study examined the effect of the simulation on nursing students' knowledge of adult nursing course before and after simulation sessions. An experimental, one-group (pretest-posttest) design was used. A convenience sample of nursing students enrolled in adult nursing course (n $=102$ ) attended the 8 simulation scenarios. A paired $\mathrm{t}$-test indicated that posttest mean knowledge of adult nursing course was higher than pre-course; however, simulation is significantly effective in helping to improve nursing students' knowledge.
\end{abstract}

\section{Keywords}

High Fidelity Simulation, Undergraduate Nursing Students, Knowledge

\section{Introduction}

Training hospitals are crowded with medical and nursing students from various academic institutions and universities, and this competition for education resources threatens the education quality of prospective graduate nurses, which is of national concern [1].

The World Health Organization (WHO) has established standards for nursing education and recommends the use of simulation [2]. Simulation is an essential technique in nursing education because it enables students to apply to clinical skills while keeping patients safe [3] and provides students the opportunity to practice clinical skills till they are able to perform certain tasks [4].

Simulation-based learning (SBL) is a technique that amplifies real-life experiences with guided, often "immersive" and duplicate aspects of real-world scenarios in a fully interactive way. It involves a process in which the student re- 
views previously discussed topics instead of "immersing" themselves in a simulation experience and undergoing debriefing with their instructor. This method of teaching helps both undergraduate health students to improve their knowledge, decision-making skills, interpersonal and communication skills and to foster a tactical attitude towards patients [5]. It is also a tool for evaluating performance [6].

Simulation-based teaching ingredients actual patient encounters with high fidelity simulators, mimicking real-time patient scenarios in a realistic, controlled environment. The student learns to learn and practice without risk and thus reduces the likelihood of medical errors. The nursing student also learns teamwork and behavioral skills, as multidisciplinary activity as a healthcare professional is essential. SBL offers multiple opportunities to rehearse and learn multiple times without causing undue harm to patients [7]. The recognition of the possible value of simulation in nursing education has been grown. Overall, the literature supports the need to include simulation as a teaching strategy in nursing curriculum. Utilization of simulation for enhancing learning outcome in nursing education is a positive and innovative method [8].

In Palestine, because of the large demand for clinical placements and a reduced number of clinical instructors, opportunities for nursing students to participate in patient care and work in clinical situations have also decreased. Hospitals in Palestine are crowded with medical and nursing students, which may affect the quality of education. There is limited data about simulation-based education used in Nursing in Palestine. Therefore, the purpose of the study was to assess the effect of simulation on nursing students' knowledge of adult nursing course before and after simulation sessions.

\section{Methods}

A cross-sectional study was conducted at lab of nursing simulation at the faculty of Nursing during October 2018-December 2018, after obtaining approval from the Institutional Ethics Committee. Written consent was taken from all the participants who were the undergraduate nursing and were exposed to SBL for over a semester (8 clinical Adult Nursing related case scenarios).

The study population is the nursing students at the Arab American University of Palestine (AAUP) from which a sample of 102 students were chosen conveniently. Inclusion criteria: nursing students, second, third, or fourth year.

Students were distributed for groups, every group 15 students. Simulation sessions held one time over 2 hours weekly for each group. Eight simulation sessions distributed on 8 weeks. In each session, one scenario demonstrated, and debriefing done on 20 minutes.

Researchers developed a validated questionnaire which composed of two parts: first part; demographic characteristics involved age, gender, and grade point average (GPA), the second part, 20 multiple choice NCLEX questions developed by researchers according to case scenarios, the questionnaire assessed for validity by sending it to five experts in nursing field with no comments. Pilot 
study was applied on 15 students and they excluded from the actual study. Reliability was assessed by Cronbach's Alpha (0.88) which is strong. The questionnaire completed at the beginning of the semester and then introduced to the same students at the end of the semester. All the questionnaires were anonymous and marked with a number. The GPA was classified to Excellent $=3.5-4$, Very good $=3-3.49$, Good $=2.5-2.99$, Fair $=2-2.49$ according to the university coding grade system

Data ware analyzed using SPSS, version 23 software was used to analyze data. Descriptive statistical method was used to interpret data using frequency and percentage for categorical. Inferential statistics was analyzed by using paired t-test. A p-value of $<0.05$ was considered as being statistically significant.

\section{Results}

Of 150 students who underwent SBL, questionnaire was distributed to 110 (absent $=40$ ), and the response rate was $73.33 \%$; as there were incompletely answered questionnaires $(n=8)$, researchers have analyzed the data of 102 students.

As shown in Table 1, more than half of the samples were males constituting $52 \%$ of the sample, and majority of the participants were 18 - 22 years old forming $82.4 \%$ of the total sample, and $46.1 \%$ of the students were with good grading GPA.

According to the results of the paired sample t-test shown in Table 2, total mean score based on the responses of pre-course was $4 \pm 3.0$, but the total mean score based on the responses of post-course was $18 \pm 2.0$. The $\mathrm{p}$-value $(\mathrm{p}=$ 0.001 ) indicating that there was statistical difference between pre course and after course regarding the effect of simulation on enhancing their knowledge of Adult nursing course.

Table 1. Sample distribution according to their demographic information $(\mathrm{N}=102)$.

\begin{tabular}{ccc}
\hline & Variable & Percent \\
\hline \multirow{2}{*}{ Gender } & Male & $52 \%$ \\
& Female & $48 \%$ \\
Age & $18-22$ yrs. & $82.40 \%$ \\
& $23-27$ yrs. & $16.70 \%$ \\
& $28-32$ yrs. & $1 \%$ \\
GPA & Excellent & $21.60 \%$ \\
& Very good & $27.50 \%$ \\
& Good & $46.10 \%$ \\
& Fair & $2.90 \%$ \\
\hline
\end{tabular}

Table 2. Total mean differences between pre and post course $(\mathrm{N}=102)$.

\begin{tabular}{lccccc}
\hline & & $\mathrm{M}$ & $\mathrm{SD}$ & $\mathrm{t}$ & $\mathrm{p}$ value \\
\cline { 2 - 5 } Adult Nursing Students & Pre-course & 4.0 & 3.0 & 14.0 & \\
& Post course & 18.0 & 2.0 & & 0.001 \\
\hline
\end{tabular}




\section{Discussion}

The purpose of this study was to evaluate the effect of simulation on the knowledge of adult nursing students before and after simulation sessions. The results showed that the knowledge of students in the post-course improved significantly particularly compared to the pre-course. This finding is consistent with the findings of other studies that show that simulation has a positive effect on enhancing learning and competence in clinical skills [9] [10] [11] [12]. This is consistent with the findings of other studies [1] [13], which showed a positive effect of simulation on improving knowledge.

The significant effects of simulation on post-adult nursing knowledge course can be attributed to many factors. The presence of a realistic patient environment involved the use of monitors that showed physiological changes and a simulated patient in which the student monitored the responses to the application of scenarios. The simulation environment enhances visual, auditory and tangible learning methods and generates different, more active and engaged responses from students [14].

Ayed \& Khalaf highlighted the importance of simulation as an effective means of creating a realistic and practical environment. In addition, the simulation scenario in the current study was followed by debriefing sessions that addressed the mistakes of the students, helping to improve the knowledge of the scenarios [8]. This is consistent with the study by Cantrell [15], who concluded that debriefing helps students to decompress and integrate the experience into their knowledge base. The debriefing session may offer the opportunity for valuable reflective learning and clarification of the content and concepts provided during the simulation scenarios. Dreifuerst determined the positive effect of debriefing, which could enhance significant learning experiences [16].

\section{Limitations, Recommendations, and Implications}

The sample was limited to baccalaureate nursing students at one Palestinian university. It is recommended that this study be replicated on a larger scale to investigate whether the significant findings of a larger, heterogeneous sample can be sustained. It is also suggested that a study including many nursing sites with various nursing programs would provide insight into the learning outcome.

The results of the current study have real implications for nursing, as simulation provides a safe, practical environment for nursing students and educators. Simulation is an effective teaching method that can be eventually adopted as a method of undergraduate teaching. Future research should be carried out to examine the sociodemographic characteristics of students and to identify which students benefit most, so that more simulation time can be allocated to them. Future research is recommended to evaluate other learning outcomes using simulation.

\section{Conclusion}

The current study adds to the growing evidence that simulation has a positive 
effect on student knowledge. Enhanced knowledge of adult nursing courses was achieved by nursing students who were trained and trained in high-fidelity simulation. The results also provide evidence to support the integration of simulation as an effective teaching method that helps to improve student knowledge. In addition, it offers nurse educators the opportunity to provide students with realistic learning experiences in a safe environment.

\section{Conflicts of Interest}

The authors declare no conflicts of interest regarding the publication of this paper.

\section{References}

[1] Akhu-Zaheya, L.M, Gharaibeh, M. and Alostaz, Z.M. (2013) Effectiveness of Simulation on Knowledge Acquisition, Knowledge Retention, and Self-Efficacy of Nursing Students in Jordan. Clinical Simulation in Nursing, 9, e335-e342. https://doi.org/10.1016/j.ecns.2012.05.001

[2] World Health Organization. Nursing \& Midwifery Human Resources for Health (2009) Global Standards for the Initial Education of Professional Nurses and Midwives. World Health Organization, Department of Human Resources for Health, Geneva, 3-36.

[3] Decker, S., Sportsman, S., Puetz, L. and Billings, L. (2008) The Evolution of Simulation and Its Contribution to Competency. The Journal of Continuing Education in Nursing, 39, 74-80. https://doi.org/10.3928/00220124-20080201-06

[4] Medley, C.F. and Horne, C. (2005) Using Simulation Technology for Undergraduate Nursing Education. Journal of Nursing Education, 44, 31-34.

[5] Morgan, P.J., Cleave-Hogg, D. and Desousa, S. (2006) Applying Theory to Practice in Undergraduate Education Using High Fidelity Simulation. Medical Teacher, 28, e10-e15. https://doi.org/10.1080/01421590600568488

[6] Gaba, D. (1999) Human Work Environment and Simulators. In: Miller, R.D., Ed., In Anaesthesia, 5th Edition, Churchill Living Stone, New York, 18-26.

[7] Ennen, C.S. and Satin, A.J. (2010) Training and Assessment in Obstetrics: The Role of Simulation. Best Practice \& Research Clinical Obstetrics \& Gynaecology, 24, 747-758. https://doi.org/10.1016/j.bpobgyn.2010.03.003

[8] Ayed, A. and Khalaf, I. (2018) The Outcomes of Integrating High Fidelity Simulation in Nursing Education: An Integrative Review. Open Journal of Nursing, 8, 292. https://doi.org/10.4236/ojn.2018.85025

[9] Alinier, G., Hunt, W.B. and Gordon, R. (2004) Determining the Value of Simulation in Nurse Education: Study Design and Initial Results. Nurse Education in Practice, 4, 200-207. https://doi.org/10.1016/S1471-5953(03)00066-0

[10] Feingold, C.E., Calaluce, M. and Kallen, M.A. (2004) Computerized Patient Model and Simulated Clinical Experiences: Evaluation with Baccalaureate Nursing Students. Journal of Nursing Education, 43, 156-163.

[11] Goldenberg, D., Andrusyszyn, M.A. and Iwasiw, C. (2005) The Effect of Classroom Simulation on Nursing Students' Self-Efficacy Related to Health Teaching. Journal of Nursing Education, 44, 310-314.

[12] Mole, L.J. and McLaffery, I.H. (2004) Evaluating a Simulated Ward Exercise for Third Year Student Nurses. Nurse Education in Practice, 4, 91-99. 
https://doi.org/10.1016/S1471-5953(03)00031-3

[13] Ackermann, A.D., Kenny, G. and Walker, C. (2007) Simulator Programs for New Nurses' Orientation: A Retention Strategy. Journal for Nurses in Staff Development, 23, 136-139. https://doi.org/10.1097/01.NND.0000277183.32582.43

[14] Steadman, R.H., Coates, W.C., Huang, Y.M., Matevosian, R., Larmon, B.R., McCullough, L. and Ariel, D. (2006) Simulation-Based Training Is Superior to Problem-Based Learning for the Acquisition of Critical Assessment and Management Skills. Critical Care Medicine, 34, 151-157. https://doi.org/10.1097/01.CCM.0000190619.42013.94

[15] Cantrell, M.A. (2008) The Importance of Debriefing in Clinical Simulations. Clinical Simulation in Nursing, 4, e19-e23.

https://doi.org/10.1016/j.ecns.2008.06.006

[16] Dreifuerst, K.T. (2009) The Essentials of Debriefing in Simulation Learning: A Concept Analysis. Nursing Education Perspectives, 30, 109-114. 